as possible to the light, as is done by those of the compass plant in a different way, and that it was therefore probable that the stomata would be found to be as numerous on the upper face of the leaf as on the lower. A microseopic examination proved the correctness of Mr. Ravenel's conjecture; the stomata are about equally numerous on the two faces. Whether the leaves take a vertical position because the stomata occupy both surfaces, or whether the stomata are so distributed because the leaves stand edgewise to the zenith, is a question. The fact is, that the two are thus correlated, and such correlation is ordinarily essential to the well-being of the plant. It may be remarked, however, that the stomata do not manifestly appear until the leaf is pretty well developed, also that this distribution of the stomata is peculiar to the species in question; at least the leaves of $B$. australis and B. leucantha, which retain their horizontal position, are provided with stomata only on their lower face. The question next arises whether $B$. perfoliata really differs in its normal phyllotaxis from its congeners. We find that it does not, that in B. australis, leucantha, and alba, and in $B$. perfoliata likewise (these being all the species at present cultivated in the Cambridge Botanic Garden), the arrangement of the leaves at the base of the main stem is of the tristichous order, but that after the first or second cycle, especially on the branches, this changes to the distichous order. The difference between $B$. perfoliata and its congeners, therefore, is not in the normal arrangement of the leaves, but in the fusion of the axis and the distribution of the stomata, adapting the foliage to its vertical position.

The form of the leaves in Baptisia perfoliata is remarkably peculiar. Most of the species have trifoliate leaves and a pair of stipules; this has to all appearance a simple and entire perfoliate leaf and no stipules. It is, however, a natural supposition that the apparently simple leaf consists either of a pair of stipules, or of such stipules and a leaflet connate into a rounded disk. This supposition Mr. Ravenel has just now had the good fortune to verify, by finding some abnormal shoots of $B$. perfoliata, one of which is in our possession. Most of its leaves are cordate-clasping rather than perfoliate, and with or without a retuse or emarginate apex, some almost two-parted so as to represent pretty obviously a pair of stipules, and one of like conformation but with an obvious terminal leaflet in the sinus! Mr. Ravenel remarks that this is a manifest step toward his own B. stipulacea; but it hardly invalidates that species, although the inflorescence and legume of the two are quite alike.-Prof. Asa Gray in Silliman's American Journal, Dec. 1871.

\title{
On a new Micrometric Goniometer Eyepiece for the Microscope.
} By J. P. Southworth.

After a few experiments by Dr. H. T. Porter and myself, we have succeeded in making an eyepiece micrometer and goniometer which equal in accuracy and surpass in simplicity and cheapness any we have seen; and we have used those of some of the best makers in this country. The objection to the eyepiece micrometers in use is the want of boldness in the division-lines, which makes 
them fatiguing and hurtful to the eyes. To overcome this objection, we were led to experiments in making micrometers by the aid of photography, which have resulted in success. The steps of the process are these :-

1st. A scale of 100 heavy Indian-ink lines, about $\frac{1}{6}$ of an inch apart, are drawn on a dead white surface of Bristol board. The lines marking every ten divisions are 6 inches long and extend one inch each side of the scale; those marking every five divisions are 5 inches long, and extend half an inch beyond the scale; the remaining lines are 4 inches long.

2nd. By photographic process for copying engravings, a negative is taken, on which the scale equals about 2 inches in length, and is intensified by mercuric chloride and potassium cyanide.

3rd. With a copying-camera and lens for taking transparent positives for the magic lantern, a transparent positive of this negative is taken on micrometer glass, reducing the scale to the length of half an inch. In this the lines are $\frac{1}{200}$ of an inch apart. After intensifying, washing, and drying, a cover of thin glass is cemented on with Canadian balsam, and the slide cut to fit the slit in the micrometer eyepiece. It can also be mounted with a spring and micrometer screw, like Jackson's micrometer. In our micrometer the lines appear to stand out in relief, and are jet-black, while the spaces between them are translucent enough to admit of the accurate measurement of the details of minute algæ and fungi to the $\frac{1}{25000}$ of an inch.

Regarding the goniometer:-

1st. A circle, about 18 inches in diameter, is drawn with Indian ink, divided into degrees. The centre is indicated by a dot, and one diameter is drawn. Every five and ten degrees are indicated by longer lines than those indicating single degrees. Every ten degrees of each quadrant is numbered, from 0 to 90 .

2nd. A negative 2 inches in diameter is taken by the process referred to above; and from this a transparent positive is taken on a circle or micrometer glass cut to fit the tube of the microscope. It is covered with a circle of thin glass cemented with balsam, and mounted to fit the tube at the focal point of a positive eyepiece. A cobweb is drawn across the diameter of the lower lens. When a crystal is to be measured, the stage is moved till the apex of the angle coincides with the centre of the goniometer, and the diameter with one side. The eyepiece is now turned till the cobweb crossing the diameter at the centre coincides with the other side of the angle. Now the number of degrees of the angle can be read at the circumference. The advantage of this over the ordinary microscopic goniometers is, that in ours the angles of the crystal and the degrees of the goniometer are on the same line of sight within the tube of the microscope, while in the ordinary goniometer the degrees are marked outside the tube. The photographic processes by which the above are made can be learned by consulting any of the standard works on photography, under the sections that treat of copying engravings and taking transparent positives.-Silliman's American Journal, Dec. 1871. 


\section{$2 \mathrm{BHL}$ Biodiversity Heritage Library}

Southworth, J P. 1872. "On a new micrometric goniometer eyepiece for the microscope." The Annals and magazine of natural history; zoology, botany, and geology 9, 175-176. https://doi.org/10.1080/00222937208696561.

View This Item Online: https://www.biodiversitylibrary.org/item/54555

DOI: https://doi.org/10.1080/00222937208696561

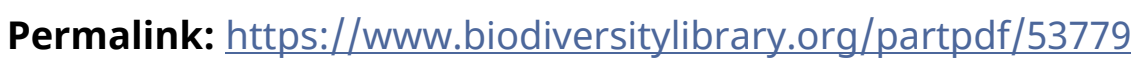

\section{Holding Institution}

Smithsonian Libraries

\section{Sponsored by}

Smithsonian

\section{Copyright \& Reuse}

Copyright Status: Public domain. The BHL considers that this work is no longer under copyright protection.

This document was created from content at the Biodiversity Heritage Library, the world's largest open access digital library for biodiversity literature and archives. Visit BHL at https://www.biodiversitylibrary.org. 